Научная статья

УДК $821.161 .1 .0-1$

DOI 10.18101/2686-7095-2021-4-52-60

\title{
РЕЦЕПЦИЯ РУССКОЙ ПОЭЗИИ РУБЕЖА ХХ-ХХІ ВВ. В СОВРЕМЕННОМ ЛИТЕРАТУРОВЕДЕНИИ
}

\author{
(C) Затеева Татьяна Владимировна \\ доктор филологических наук, профессор, \\ Бурятский государственный университет имени Доржи Банзарова \\ Россия, 670000, г. Улан-Удэ, ул. Ранжурова, 6 \\ vlatat1954@yandex.ru \\ (C) Каратуева Валерия Константиновна \\ магистр, \\ ТРК «Тивиком» \\ Россия, 670000, г. Улан-Удэ, ул. Борсоева, 13 \\ valeria-06.96@mail.ru
}

Аннотация. Содержание статьи составляет анализ критической и литературоведческой рецепции современной русской поэзии в критике и литературоведении рубежа XX-XXI вв. Обращение к исследованиям М. Н. Эпштейна, Н. А. Ловчинского, И. И. Плехановой позволило выявить и определить особенности оценок постмодернистской поэзии как крупнейшего явления в литературе конца XX в. К анализу также привлечены исследовательские стратегии В. А. Мескина, В. А. Зайцева, Е. С. Зинуровой, С. П. Гудковой, У. Ю. Вериной и др., характерные для литературоведения начала XXI в., направленные на определение новых стилевых течений и направлений, характеризующих современную поэзию последних двух десятилетий, ее жанровое своеобразие и поэтику. Анализ основных положений статей вышеуказанных литературоведов позволил определить специфику новых подходов, которые заключаются в создании типологической картины современной русской поэзии; в осмыслении интертекстуальности как взаимодействия современных авторов с поэтамиклассиками и установления культурного диалога. В статье делается вывод о наличии в современном литературоведении, изучающем состояние русской поэзии рубежа XX-XXI вв., многообразия исследовательских практик: жанрологических, типологических, поэтологических, интертекстуальных.

Ключевые слова: литературоведение, рецепция, современная русская поэзия, жанровые разновидности, поэтика, постмодернизм, неореализм, интертекстуальность, традиция, новаторство.

\section{Для цитирования}

Затеева T. В., Каратуева B. K. Рецепция русской поэзии рубежа XX-XXI вв. в современном литературоведении // Вестник Бурятского государственного университета. Филология. 2021. Вып. 4. С. 52-60. 
T. В. Затеева, В. К. Каратуева. Рецепция русской поэзии рубежа XX-XXI вв. в современном литературоведении

История современной поэзии пишется на наших глазах ${ }^{1}$. И поэтому ответов на вопросы, кто из поэтов последних десятилетий войдет в анналы истории русской литературы, каких поэтов новые поколения читателей будут называть «властителями душ», современное литературоведение пока не имеет. На самом деле вопросов, связанных с современной поэзией, гораздо больше, и все они нуждаются в осмыслении.

Цель настоящей статьи заключается в анализе избранных работ современных отечественных критиков и литературоведов, исследующих специфику русской поэзии конца XX - начала XXI в.

Начнем с того, что критическая и литературоведческая рецепция постмодернистской поэзии как символа новой литературы последней четверти XX в. оказалась богатой на наблюдения, анализ, интерпретацию, итоговые обобщения и прогнозы ${ }^{2}$.

В своей книге «Постмодерн в русской литературе» М. Н. Эпштейн отмечает, что проявление постмодернистской эстетики в русской поэзии, а не прозе последней четверти XX столетия - закономерное явление, сходное с предшествующими литературными эпохами романтизма, символизма, модернистских течений. Объяснение этому явлению он усматривает в особом характере поэзии, быстрее реагирующей на эксперимент и экспрессию в литературе. Причем постмодернизм «возникает сразу как «общепоэтическая ситуация», не просто как одна группа, школа или стилевое течение, но как соотношение стилей в широком диапазоне, простирающемся от концептуализма до метареализма... Постмодернизм не сводится ни к одному из этих течений, но выступает в них и «между ними» как потенциальность новой большой художественной системы, способной порождать самые разные течения и индивидуальные стили...» [14, с. 127].

Художественной идеей, которая могла бы объединить поэтовпосмодернистов, по М. Н. Эпштейну, является «идея культуры», «второй рефлексивный слой восприятия». «В художественном развитии, которое долгое время двигалось путем освоения все новых пластов действительности: общество (соцреализм), личность (исповедальная лирика), природа (деревенская поэзия), произошел как бы скачок самосознания, самоудвоения, поскольку в область освоения вступила такая мощная система, объемлющая все стороны действительности, как культура» $[14$, с. 130].

В этом высказывании одного из апологетов постмодернизма есть то, что часто ускользает из поля зрения исследователей, занимающихся изучением совре-

${ }^{1}$ В настоящей статье использован материал публикации: Затеева Т. В., Каратуева В. К. Современная русская поэзия в отзывах критиков и литературоведов // Филологическое образование и современный мир: материалы XVII Международной научно-практической конференции. Чита: Изд-во ЗабГУ, 2021. Ч. 1. С. 52-59.

${ }^{2}$ Ильин И. П. Постструктурализм. Деконструктивизм. Постмодернизм. Москва, 1996; Липовецкий М. Н. Русский литературный постмодернизм (очерки исторической поэтики). Екатеринбург, 1997; Скоропанова И. С. Русская постмодернистская литература. Москва, 2001; Эпштейн М. Н. Постмодерн в русской литературе. Москва, 2005; Погорелова И. Ю. Концептуалистская стратегия как жанровая система творчества Д. А. Пригова. Пятигорск, 2012; и др. 
менной поэзии: признание новизны постмодернистской поэзии происходит на фоне констатации основных объектов поэзии (разных пластов действительности) предшествующей литературной эпохи.

Литературное бытие постмодернистской поэзии оказалось ярким, но кратковременным. М. Н. Эпштейн считает, что к концу 1990-х гг. постмодернизм исчерпал себя, и вводит новое понятие «постмодерность», которое проявляет себя за пределами постмодернизма $[15$, с. 10$]$.

На это обращает внимание и Н. А. Ловчинский, задаваясь вопросами, что представляет собой это поэтическое явление в первые годы XXI в., каких авторов и какие тексты можно называть постмодернистскими и какими критериями отбора следует руководствоваться. Он считает, что постмодернизм «имеет все права на существование до тех пор, пока не изжили себя основополагающие реалии современной постиндустриальной эпохи, составившие его базис...» [8, с. 95]. Среди этих реалий автор выделяет специфический стиль постмодернистской поэзии, характеризующий, по его словам, поэзию не только старшего поколения постмодернистов (Т. Кибиров, Д. Пригов, Л. Рубинштейн, Е. Шварц), но и младшего поколения (А. Алехин, П. Барскова, И. Кригер, В. Степной, В. Іванів, Д. Григорьев и др.). Выделяются их общие особенности: «гиперэкзистенциальный», полный внутренних конфликтов характер их поэзии, актуализация темы человека и его места в пространстве, роли в мироздании: «Конфликты политические, социальные, семейные в современной русской постмодернистской поэзии утратили свою актуальность; лирический герой остается один на один с вещами, природой, космосом, временем жизни и смерти» [8, с. 97].

О значимости постмодернистской поэзии в первые годы нового тысячелетия размышляет также И. И. Плеханова, которая акцентировала внимание на гуманистическом потенциале их творчества: «Современный поэтический процесс до самого конца XX в. разворачивался в атмосфере постмодернистской деконструкции, но никак не деградации духовных оснований творчества. Доминировали и сосуществовали два направления - неовангард и модернистская неоклассика - и оба выстраивали свой метафизический образ мира и творчества. $[11$, с. 6]. Краеугольный камень литературного постмодерна составляют «защита неотменяемой системы ценностей и выработка посткризисного гуманистического миропонимания, креативной антропологии и образа мышления, соответствующего новой картине мира» $[11$, с. 6$]$.

Все же постмодернистская поэзия приходит к кризису, а затем к почти полному исчезновению на исходе первого десятилетия XXI в. Поэт-постмодернист И. Ф. Жданов констатирует: «Постмодернизм умер». И причины на то есть. Главная из них, по мнению В. А. Мескина, заключается в том, что своим успехом русская постмодернистская литература была обязана в первую очередь социально-историческим обстоятельствам последних десятилетий XX в., определившим ее характер и развитие и исчерпавшим свой потенциал в первые годы нового тысячелетия.

При этом уход постмодернизма из литературной практики не сказывается на его научной рецепции. Более того, в начале XXI в. в литературоведении сохраняется устойчивый интерес к постмодернистской поэзии - ее поэтике, стилевым течениям, творчеству отдельных поэтов-постмодернистов. Более того, твор- 
T. В. Затеева, В. К. Каратуева. Рецепция русской поэзии рубежа XX-XXI вв. в современном литературоведении

чество писателей-постмодернистов в нашей стране оказалось, как говорят, не столь репрезентативно, как его теоретическая рефлексия.

Падение удельного веса постмодернистской поэзии, как и всей литературы этого направления, так и не ставшего мейнстримом в литературном процессе последней четверти XX в., совпало в начале XXI столетия с активизацией реалистической литературы, которую часто называют неореализмом. По мнению В. А. Мескина, особенностью нового этапа в современной русской литературе является то, что «реалистическая традиция решительно отодвигает традицию постмодернистскую» $[9$, с. 6]. Повлияли на падение интереса к постмодернизму его преувеличенное внимание к игровой поэтике и интертекстуальной игре, обесценившим Слово и тем самым способствовавшим утрате доверия к Литературе.

Возрождаются в условиях завершения кризисного времени потребность писателей «реально изображать жизнь», стремление к «миметическому творчеству и классическому триединству, отображению красоты, неотделимой от добра, истины. Обобщенно, потому что реализм современный, как и в прошлом, многолик, его творческая лаборатория открыта для принятия приемов, рожденных «чужими» художественными экспериментами» [9, с. 7].

Высказанное В. А. Мескиным суждение касается прозы. Думается, что оно в полной мере может быть отнесено и к тем изменениям, которые происходят в современной поэзии, также демонстрирующей потребность к всестороннему изображению человека и его поисков тех начал жизни, которые позволяют ему любить, верить и надеяться.

Есть основания утверждать, что в первое десятилетие XXI в. изменения начали происходить также в российском литературоведении, расширившем область своих интересов. Показательной в этом плане является статья В. А. Зайцева, лейтмотивом которой является мысль о наступлении нового этапа в русской современной поэзии с его двумя основными стилевыми течениями: реалистическим и неоклассическим - авангардистским и постмодернистским: «с одной стороны, реализм и романтизм, а с другой - особенно активизировавшиеся в последнее время авангард и постмодернизм. Таким образом, в основном реализуется движение современной поэзии, хотя картина, очевидно, более сложная, о чем свидетельствуют попытки ввести новые дефиниции и термины - от «метареализма» (под этим названием выступают такие разные поэты, как А. Еременко, И. Жданов, А. Парщиков) ... и до так называемого почвенного направления (Ю. Кузнецов, Н. Рубцов и др.)...» [6, с. 18].

Далее он уточняет типологическую характеристику современной поэзии, первым направлением называя реалистическое, связанное с обновлением и развитием традиций русской классики, реалистической лирики и представленное поздним творчеством В. Корнилова, А. Кушнера, О. Чухонцева, а из поэтов русского зарубежья - Ю. Кублановским, Н. Горбаневским и др. [6, с. 18]. Второе направление основывается на обращении «к опыту авангарда, в частности, в творчестве А. Вознесенского, К. Кедрова, В. Сосноры...» [6, с. 22]. Характеризуя третье направление - постмодернистское, В. А. Зайцев пишет: «Поиск новых возможностей слова на путях постмодернизма обнаруживается уже в 1980-е гг. у «концептуалистов» (Д. А. Пригов, Л. Рубинштейн), «иронистов» (Т. Кибиров, И. Иртеньев, Н. Искренко), «метареалистов» (И. Жданов, А. Еременко, А. Пар- 
щиков), «куртуазных маньеристов» (В. Степанцов, В. Пеленягре, Д. Быков и др.)» $[6$, с. 26$]$.

Причем в поэзии И. Ф. Жданова и О. А. Седаковой В. А. Зайцев выделяет ярко выраженное индивидуальное своеобразие, отражающееся в выборе тем, в позиции лирического героя, открытого новому времени с его вызовами и идеями, авторском стиле и поэтике. Это свидетельствует о новаторском характере исследования ученого.

Творческую эволюцию И. Ф. Жданова он показал как путь от стихов, «насыщенных сложными субъективными ассоциациями», «к большей естественности и органичности в осмыслении мира, истории, народного бытия, собственной судьбы, не отказываясь при этом от устремления к «запредельному», к «метареальности». Это путешествие по «безграничной вселенной», суть которой составляет вечное движение от рождения до смерти, всеобъемлющее и трагическое в своей основе; и конфликт природы и цивилизации, также осмысленный поэтом в трагедийном ключе» [6, с. 33]. Исследователь выделяет в творчестве поэта философско-поэтическую масштабность мысли и образа человека, для которого «мирозданье - всего лишь черта горизонта» [6, с. 32-33]. Заметим, что в свете этой тенденции объяснимым является обращение Жданова к художественной фотографии, в которой он так же, как когда-то в поэзии, стремится живописать многообразие мира.

Позиционируя О. А. Седакову как поэта вне каких-либо групп и течений, В. А. Зайцев акцентирует внимание на таких свойствах ее поэзии, как глубинное мироощущение и оригинальный стих. Их основа - не только высокий профессионализм, но и целостный, многогранный, одухотворенный художественный мир поэтессы, редкостное ощущение слова, умение «слышать поэзию языка» $[6$, c. 35]. Ключ к поэзии Седаковой заключен в ее собственном лирическом признании: «Поэзия земли не умирает», что позволяет говорить не о книжном, а земном характере ее поэзии. Она обладает даром переводить «земное, обыденное, злободневное» в «область высокого искусства — в надмирное, бытийное, вечное», не избегать «прозы жизни», но приобщать ее к вечным темам, сюжетам, образам [6, c. 35].

Учитывая философско-эстетическую ориентацию И. Ф. Жданова и О. А. Седаковой на широкий круг предшественников и современников из отечественной и мировой поэзии, В. А. Зайцев правомерно относит их творчество к четвертому направлению - «неоклассической поэзии, во многом и по существу отличающейся и даже противостоящей постмодернистской линии, будь то концептуализм, иронизм или, тем более, «куртуазный маньеризм» и прочие, возникавшие в последние десятилетия XX в. и столь же быстро распадавшиеся и уходившие с литературной «арены» школы, группы, течения и направления» [6, с. 37-38].

Не менее значимым направлением в литературоведении начала XXI в. является изучение жанровой системы поэзии начала XXI в. Известно, что одним из характерных признаков современной поэзии явился жанровый эксперимент, когда уже в конце XX в. поэты осуществили модернизацию традиционных поэтических жанров, ломая границы жанров, создавая новые жанровые формы.

Вопросу жанрового потенциала крупных поэтических форм посвящена монография С. П. Гудковой [5]. На материале произведений поэтов, принадлежа- 
T. В. Затеева, В. К. Каратуева. Рецепция русской поэзии рубежа XX-XXI вв. в современном литературоведении

щих к разным художественно-стилевым направлениям: А. Вознесенского, Е. Рейна, О. Чухонцева, Т. Кибирова, Л. Лосева, О. Хлебникова, О. Николаевой, С. Кековой, С. Завьялова, Г. Шульпакова и др., были высказаны мысли о дискуссионности, продуктивности времени, когда уживались самые разные поэтические практики. Отмечено значение не только собственно литературных факторов, но и внелитературных, таких как разветвленная сеть периодических изданий, в том числе ориентированных исключительно на поэзию («Арион», «Дети Ра» и др.), интернет-ресурсы, включающие авторские и специализированные блоги («ЛитКульт» и др.), конкурсы, премии, способствующие продвижению поэзии к читателю.

С. П. Гудкова так же, как и другие исследователи, выделяет в поэзии «традиционную» и «авангардную» линии, берущие свое начало в советской литературе. Между тем, по мнению автора, тяготение к эксперименту — привилегия не только авангардистов, но и «традиционалистов», также стремящихся к обновлению классической традиции. Достаточно вспомнить Е. А. Евтушенко, А. А. Вознесенского, О. Чухонцева, И. Лиснянскую, А. Наймана, Т. Бек, Ю. Кублановского, О. Николаеву, С. Кекову и др., которые, как и Д. Пригов, Г. Сапгир, Вс. Некрасов, Л. Рубинштейн, Т. Кибиров, И. Жданов, А. Парщиков, Е. Шварц, были не подражателями или умелыми копиистами, а талантливыми экспериментаторами [5].

В центре внимания находится также проблема обновления жанровой системы современной поэзии. Для У. Ю. Вериной современная поэзия представляет собой благодатный материал, поскольку, «обладая свойством совпадения с текущим моментом, откликается на перемены и формирует обновленный художественный язык» [4, с. 4]. Исследователь рассматривает вопросы модификации жанра лирического стихотворения, баллады и «длинного» верлибра; выявляет роль сверхтекстовых единств как показателей жанровых поисков современных поэтов [4, с. 4]. Решение этих задач обусловило новаторский характер ее исследования.

О важности наблюдений над изменениями, происходящими в поэтической среде рубежа XX-XXI вв., об актуализации исследования современной поэзии в контексте интертекстуальности свидетельствует статья Е. С. Зинуровой [7]. Говоря о трудности систематизации и дифференциации современной поэзии, об отсутствии в ней ярко выраженных литературных объединений и содружеств, подобных «Ордену куртуазных маньеристов», автор статьи правомерно ссылается на известный доклад Д. В. Кузьмина «Русская поэзия в начале XXI в.», вышедший в самом начале третьего тысячелетия [7], в котором речь шла об исчерпанности еще недавно широко известных литературных практик. Примеры относительно новых практик редки и в достаточной мере условны. Для Зинуровой так же, как и для Кузьмина, факт распада былых поэтических школ и групп, исчезновения пейзажной и деревенской лирики (добавим от себя - любовной лирики) очевиден.

Однако данная статья интересна не упадочническим или ностальгическим настроением, хотя оно, безусловно, сквозит в словах автора («Проще сказать, чего в поэзии теперь нет»), а стремлением осмыслить в современной поэзии тот потенциал, который является залогом ее развития. В связи с этим выдвинутый 
Зинуровой тезис о важности восстановления диалога между современными поэтами и представителями классической традиции представляется особо значимым: «Связывать поколения помогает интертекстуальность, выполняющая в данном случае функцию ведения диалога между классиками и современными поэтами» [7, с. 73]. Конечно, интертекстуальность - это только один из возможных путей развития современной поэзии, которая, как и раньше - и в XIX в., и в XX в., рождается, дышит текущей жизнью, ищет свой «нерв», не боится экспериментов, ждет своих конгениальных читателей - критиков и литературоведов, но более всего - истинных любителей поэзии.

Из авторов: критиков, литературоведов, статьи которых посвящены исследованию особенностей становления новейшей поэзии, а также размышлениям о современном читателе поэтических текстов, особенностях его восприятия поэзии, о падении читательской культуры в обществе, - считаем необходимым назвать Е. В. Абдуллаева [1], Е. В. Степанова [12], О. Ю. Мурашко [10], Я. С. Сущего [13]; О. Андрееву [2], Е. И. Вежлян (Воробьеву) [3].

Новый пласт современной русской поэзии - «новейшая поэзия» последнего десятилетия представляет собой мозаичное полотно, как это было и на рубеже XX-XXI вв. Ей еще предстоит отлиться в законченные формы. В ней продолжают вести творческий поиск поэты, вошедшие в литературу в последнее десятилетие XX столетия и пережившие и громкие минуты славы, и творческие взлеты, и разочарования, и кризис. В поэзию входят молодые, их много, разглядеть в них будущих мэтров и классиков сегодня не просто, но они дерзки, энергичны, плодовиты, талантливы, пробуют свои силы в различных жанровых формах, изобретают свой поэтический язык, экспериментируют, ищут опору в традиции и отталкиваются от нее - словом, действуют так же, как их предшественники, многие из которых уже вошли в пантеон русской поэзии. А значит, пессимистическое признание Т. Кибирова: «Поэзия живет тогда, когда она читается. Сейчас поэзию не читают», преждевременно.

Таким образом, в оценке русской поэзии рубежа XX-XXI вв. современная критика и литературоведение в последние два десятилетия, с одной стороны, постепенно преодолевают нигилистический опыт филологической науки первого постсоветского периода. С другой стороны, успешно осваивают достижения зарубежного литературоведения, позволяющего актуализировать в творчестве современных поэтов новые аспекты, демонстрируют различные методологические подходы и методики анализа и интерпретации поэтических текстов. Изучение своеобразия современной поэзии, ее сущностных признаков, а также ярких поэтических индивидуальностей осуществляется в контексте жанрологических, типологических, поэтологических и интертекстуальных исследовательских практик.

\section{Литература}

1. Абдуллаев Е. В. Кому нужна современная поэзия // Арион. 2019. № 1. С. $23-43$. Текст: непосредственный.

2. Андреева О. Как вернуть читателя поэзии // Prosōdia. 2015. № 3. С. 227-229. Текст: непосредственный.

3. Вежлян Е. И. Современная поэзия и проблема ее «нечтения» (опыт реконцептуализации) // НЛО. 2017. № 1. С. 270-290. Текст: непосредственный. 
T. В. Затеева, В. К. Каратуева. Рецепция русской поэзии рубежа XX-XXI вв. в современном литературоведении

4. Верина У. Ю. Обновление жанровой системы русской поэзии рубежа XX-XXI веков. Минск: Изд-во БГУ, 2017. 307 с. Текст: непосредственный.

5. Гудкова С. П. Современная русская поэзия: (проблематика, поэтика, судьбы крупных жанровых форм): монография. Саранск: Изд-во Мордовского ун-та, 2010. 298 с. Текст: непосредственный.

6. Зайцев В. А. О художественно-стилевых течениях в русской поэзии XXI века // Вестник МГУ. Сер. Филология. 2009. № 4. С. 16-38. Текст: непосредственный.

7. Зинурова Е. С. Русская поэзия рубежа XX-XXI веков: векторы развития // Вестник РУДН. Сер. Литературоведение. Журналистика. 2016. № 2. С. 69-76. Текст: непосредственный.

8. Ловчинский Н. А. Современная русская постмодернистская поэзия: отличительные черты и критерии отбора материала для научного исследования // Вестник Челябинского государственного университета. Сер. Филология. Искусствоведение. 2009. Вып. 43(181). С. 95-97. Текст: непосредственный.

9. Мескин В. А. Реализм - постмодернизм в российской литературе вчера и сегодня // Вестник РУДН. Сер. Литературоведение. Журналистика. 2014. № 4. С. 5-10. Текст: непосредственный.

10. Мурашко О. Ю. О современной поэзии // Творческая гостиная. URL: http://artrosa.ru/contacts (дата обращения: 08.04.2021). Текст: электронный.

11. Плеханова И. И. Русская поэзия рубежа XX-XXI веков: учебное пособие. Иркутск: Изд-во Иркутского гос. ун-та, 2007. 439 с. Текст: непосредственный.

12. Степанов Е. В. Современная поэзия: тенденции начала XXI века // Дети Ра. 2008. № 9(47). С. 113-122. Текст: непосредственный.

13. Сущий С. Я. Современная русская поэзия - стадия ливня // Prosōdia. 2015. № 3. С. 217-226. Текст: непосредственный.

14. Эпштейн М. Н. Литературные движения. Метареализм. Концептуализм. Арьергард // Постмодерн в русской литературе. Москва: Высшая школа, 2005. С. 127-196. Текст: непосредственный.

15. Эпштейн М. Н. Постмодерн в России: литература и теория. Москва: Изд. Р. Элинина, 2000. 367 с. Текст: непосредственный.

Статья поступила в редакцию 19.11.2021; одобрена после рецензирования 29.11.2021; принята к публикации 10.12.2021.

\section{RECEPTION OF RUSSIAN POETRY \\ OF THE TURN OF THE $20^{\text {th }}$ CENTURY \\ IN MODERN LITERARY STUDIES}

Tatyana V. Zateyeva

Dr. Sci. (Phil.), Prof.,

Dorzhi Banzarov Buryat State University

6 Ranzhurova St., Ulan-Ude 670000, Russia

vlatat1954@yandex.ru

Valeria K. Karatueva

Magister,

«Tivicom» Television and Radio Broadcasting Company

13 Borsoeva St., Ulan-Ude 670000, Russia

valeria-06.96@mail.ru 
Abstract. The article presents an analysis of the critical and literary reception of contemporary Russian poetry in literary studies of the turn of the $20^{\text {th }}$ century. The address to researches of M. N. Lipovetzky, M. N. Epstein, I. I. Plekhanov allowed us to reveal the peculiarities of evaluating post-modern poetry as the most prominent phenomenon in the literature of the turn of the $20^{\text {th }}$ century. The analysis also involved the important for literary studies of the beginning of the $21^{\text {st }}$ century strategies of V. A. Meskin, V. A. Zaitsev, E. S. Zinurova, S. P. Gudkova, U. Yu. Verina and others, aimed at the defining new stylistic movements, which characterize the modern poetry of the last two decades, its genre uniqueness and poetics. The conceptual issues considered in the articles by the authors mentioned above allowed us to define the specificity of new approaches, which consist in the creation of a typological picture of contemporary Russian poetry, comprehension of intertextuality as the interaction of modern authors with classic poets, and advancement of cultural dialogue. We have come to the conclusion that there is a diversity of research practices (genrelogical, typological, poetic, intertextual) in contemporary literary studies of the Russian poetry of the turn of the $20^{\text {th }}$ century.

Keywords: literary studies, reception, Russian poetry, genre types, poetics, postmodernism, neorealism, intertextuality, tradition, innovation.

\section{For citation}

Zateyeva T. V., Karatueva V. K. Reception of Russian Poetry of the turn of the $20^{\text {th }}$ Century in Modern Literary Studies. Bulletin of Buryat State University. Philology. 2021; 4: 52-60 (In Russ.).

The article was submitted 19.11.2021; approved after reviewing 29.11.2021; accepted for publication 10.12.2021. 